\title{
Inhibition of cell motility and invasion by HangAmDan-B in NCI-H460 human non-small cell lung cancer cells
}

\author{
YONG JUN CHOI $^{1}$, DONG YEOK SHIN ${ }^{2}$, YEON-WEOL LEE ${ }^{1}$, CHONG KWAN CHO $^{1}$, \\ GI-YOUNG KIM ${ }^{3}$, WUN-JAE KIM ${ }^{4}$, HWA SEUNG YOO ${ }^{1}$ and YUNG HYUN CHOI ${ }^{2,5}$ \\ ${ }^{1}$ East-West Cancer Center, Dunsan Oriental Medical Hospital of Daejeon University, Daejeon 302-122; \\ ${ }^{2}$ Department of Biochemistry and Research Institute of Oriental Medicine, Dongeui University College of \\ Oriental Medicine, Busan 614-052; ${ }^{3}$ Faculty of Applied Marine Science, Cheju National University, \\ Jeju 690-756; ${ }^{4}$ Department of Urology, Chungbuk National University College of Medicine, \\ Cheongju 361-763; ${ }^{5}$ Department of Biomaterial Control (BK21 program), Graduate School and \\ Blue-Bio Industry Regional Innovation Center, Dongeui University, Busan 614-714, Republic of Korea
}

Received June 27, 2011; Accepted August 8, 2011

DOI: $10.3892 / o r .2011 .1440$

\begin{abstract}
Correlation between inhibition of cell motility and anti-invasive activity by the water extract of HangAmDan-B (HAD-B), a crude extract of eight Korean medicinal animals and plants, in NCI-H460 human non-small cell lung cancer (NSCLC) cells was investigated. Within the concentrations that were not cytotoxic, HAD-B induced significant concentrationdependent inhibition of cell motility and invasiveness of NCI-H460 cells. Treatment with HAD-B resulted in dosedependent inhibition of the activities of matrix metalloproteinase (MMP)-2 and MMP-9, and this was correlated with a decrease in expression of their mRNA and proteins, and upregulation of tissue inhibitors of metalloproteinase (TIMP)-1 and TIMP-2 expression. Anti-invasive activity of HAD-B was also found to be associated with increased tightness of the tight junction (TJ), as demonstrated by an increase in transepithelial electrical resistance. In addition, the present results indicated that treatment with HAD-B resulted in repression of the levels of claudin family members, which are major components of TJs that play a key role in control and selectivity of paracellular transport. Although further studies are needed, findings from the present study indicate that TJs and MMPs are critical targets
\end{abstract}

Correspondence to: Dr Hwa Seung Yoo, Department of East-West Cancer Center, College of Oriental Medicine, Daejeon University, Daejeon 301-724, Republic of Korea

E-mail: altyhs@hanmail.net

Dr Yung Hyun Choi, Department of Biochemistry, Dongeui University College of Oriental Medicine, Busan 614-052, Republic of Korea

E-mail: choiyh@deu.ac.kr

Key words: HangAmDan-B, NCI-H460 cells, invasion, tight junction, matrix metalloproteinases of HAD-B-induced anti-invasiveness in NCI-H460 NSCLC cells.

\section{Introduction}

Metastasis is a sequential multi-step process that ultimately leads to outgrowth of the cancer in a different organ from the one in which it originated. The process involves several steps: invasion of adjacent tissues, intravasation, transport of cancer cells through the circulatory system, arrest at a secondary site, extravasation, and growth in a secondary organ (1-3). Therefore, inhibition of tumor cell migration and invasion are important mechanisms in the anti-metastatic properties of anti-cancer drugs.

Matrix metalloproteinases (MMPs) are a family of zincdependent endopeptidases, which are known to process a broad spectrum of cell surface molecules and to function in several important biological processes. Collectively, MMPs are capable of cleaving virtually all extracellular matrix (ECM) substrates, and degradation of matrix is a key event in progression, invasion, and metastasis of potentially malignant and malignant lesions $(4,5)$. Among various MMPs, MMP-2 and MMP-9 (known as gelatinase $\mathrm{A}$ and gelatinase $\mathrm{B}$, respectively) appear to play an important role in tumor invasion and metastasis, and are highly expressed in epithelial cancer cells $(6,7)$. Tissue inhibitors of metalloproteinases (TIMPs) are naturally occurring inhibitors of MMPs, which inhibit the catalytic activity of MMPs through binding to activated MMPs and control breakdown of ECM (8). TIMPs can also inhibit proliferation, invasion, and metastasis of malignant cells. Disturbance in balance of MMPs and TIMPs is found in various pathologic conditions, including cancer (9). Therefore, balance between MMPs and TIMPs plays a vital role in maintaining the integrity of healthy tissues, and the usefulness of MMP inhibitors, as well as TIMP activators, as chemotherapeutic agents for treatment of malignant cancer is anticipated.

In epithelial cells, several specialized and distinct intercellular structures, including the gap junction, tight junction 
(TJ), adherens junction (AJ), and desmosome, are responsible for establishment of contact between neighboring cells. Among these, the most apical of these are the TJs, which form tight seals between cells and the intercellular space. Within a cell, TJ strands act as a fence, which regulates paracellular movement of ions, small molecules, and membrane proteins between the apical and basolateral surfaces, thereby maintaining the apical-basal polarity of the cell $(10,11)$. They also act as a barrier to paracellular flux of water, solutions, and transmigration of other cells. In precancerous lesions of epithelia and cancerous epithelia, TJ strands become disorganized or are lost altogether, so that TJs become 'leaky', as indicated by decreased resistance to electrical current (transepithelial electrical resistance; TER) and increased paracellular permeability of markers $(10,11)$. Claudins, which are key integral membrane proteins that form the backbone of TJs, can form homodimers or heterodimers to produce paired strands between adjacent cells, thereby determining the characteristic permeability properties of different epithelial tissues $(12,13)$. Recent studies have provided evidence demonstrating aberrant expression of claudins in various cancers, as well as their association with development and progression of cancer, which suggests that they have key cellular functions that are distinct from their roles in TJ-complexes (14-18). However, the exact role of claudin overexpression and the functional importance of these proteins in development of cancer remain unclear.

HangAmDan-B (HAD-B) is composed of nine products from species of Korean medicinal plants and animals (Table I), and has been used in oriental medicine for treatment of cancer patients for enhancement of immune function and activation of vital energy. Significant prevention of basic fibroblast growth factor (bFGFs)-induced human umbilical vein endothelial (HUVE) cell proliferation, adhesion, migration, and capillarylike tubular network formation by HAD-B has recently been reported (19); however, the anti-cancer mechanisms of HAD-B have not yet been well clarified. Therefore, the present study attempted to elucidate the anti-metastatic potentials of HAD-B in human non-small cell lung cancer (NSCLC) NCI-H460 cells and the underlying intracellular signal transduction pathways involved in inhibition of metastasis. Results of this study demonstrated that HAD-B inhibits cell motility and invasion of NCI-H460 cells through modulation of the activities of MMPs and the levels of TJ-associated factors.

\section{Materials and methods}

Cell culture and preparation of HAD-B. NSCLC NCI-H460 cells were obtained from the American Type Culture Collection (Rockville, MD, USA) and cultured in RPMI-1640 medium (Gibco BRL, Gaithersburg, MD, USA) supplemented with $10 \%$ fetal bovine serum (FBS) and $1 \%$ penicillin-streptomycin in a $37^{\circ} \mathrm{C}$ incubator with $5 \% \mathrm{CO}_{2}$. HAD-B was provided from the East-West Cancer Center of the Dunsan Oriental Medical Hospital of Daejeon University (Daejeon, Korea) (Table I). Water extract of HAD-B was prepared by extraction of HAD-B powder with 10 times $(\mathrm{v} / \mathrm{w})$ the amount of distilled water at room temperature for $24 \mathrm{~h}$. The extract was centrifuged at $1000 \mathrm{x} g$ for $30 \mathrm{~min}$, followed by filtering and lyophilization. The extract powder was dissolved directly in distilled water (19).
Table I. Ingredients of HAD-B.

Scientific name

Relative amount (mg)

Panax notoginseng Radix
Cordyceps Militaris
Santsigu Tuber
Ginseng Radix
Bovis Calculus
Margarita
Bostaurus var.domesticus Gmelin
Commiphora myrrha

84.0

64.0

64.0

64.0

64.0

64.0

48.0

48.0

Total amount (1 capsule)

500.0

MTT assay. For the cell viability study, NCI-H460 cells were grown to $70 \%$ confluence and treated with various concentrations of HAD-B for $48 \mathrm{~h}$. Following treatment, cell viability was determined using the 3-(4,5-dimethylthiazol-2-yl)-2,5-diphenyl-tetrazolium bromide (MTT, Sigma Chemical Co., St. Louis, MO, USA) assay, which is based on the conversion of MTT to MTT-formazan by mitochondrial enzymes.

Wound healing migration assay. NCI-H460 cells were grown to confluence on $30-\mathrm{mm}$ cell culture dishes coated with rat tail collagen $(20 \mu \mathrm{g} / \mathrm{ml}$, BD Biosciences, Bedford, MA, USA). A scratch was made in the cell layer with a pipette tip. After washing with PBS, serum-free media (to prevent cell proliferation) containing $0.5 \mathrm{mg} / \mathrm{ml}$ of HAD-B was added. Photographs of the wounded area were taken immediately after the scratch was made and 12, 24, and $48 \mathrm{~h}$ later in order to monitor movement of cells into the wounded area (20).

In vitro invasiveness assay. Matrigel invasion assays were used for assessment of the ability of NCI-H460 cells to penetrate ECM in the presence or absence of HAD-B. Briefly, cells were exposed to 0.3 or $0.5 \mathrm{mg} / \mathrm{ml}$ of HAD-B for $6 \mathrm{~h}$, and treated cells $(50,000)$ were then plated onto the apical side of Matrigel-coated filters in serum-free medium containing 0.3 or $0.5 \mathrm{mg} / \mathrm{ml}$ of HAD-B. Medium containing $20 \%$ FBS was placed in the basolateral chamber to function as a chemoattractant. After $48 \mathrm{~h}$, cells on the apical side were wiped off with a Q-tip. Cells on the bottom of the filter were stained with hematoxylin and eosin Y (Sigma Chemical Co.) and counted (three fields of each triplicate filter) using an inverted microscope (20).

Measurement of TER. TER values were measured with an EVOM Epithelial Tissue Voltohmmeter (World Precision Instruments, FL, USA), equipped with a pair of STX-2 chopstick electrodes. Briefly, NCI-H460 cells were seeded into the $8.0 \mu \mathrm{m}$ pore size insert (upper chamber) of a Transwell ${ }^{\circledR}$ (Corning Costar Corp., NY, USA) and allowed to reach full confluence, after which fresh medium was replaced for further experiments. Inserts without cells, inserts with cells in medium, and inserts with cells with 0.3 or $0.5 \mathrm{mg} / \mathrm{ml}$ of HAD-B were treated for $48 \mathrm{~h}$. Electrodes were placed at the upper and lower chambers, and resistance was measured with the volt-ohm meter. 
Table II. Sequences of the primer pairs employed in the RT-PCR reactions.

\begin{tabular}{ll}
\hline Name & \multicolumn{1}{c}{ Sequence of primers } \\
\hline TIMP-1 & \\
Sense & 5'-TGG-GGA-CAC-CAG-AAG-TCA-AC-3' \\
Antisense & 5'-TTT-TCA-GAG-CCT-TGG-AGG-AG-3' \\
TIMP-2 & \\
Sense & 5'-GTC-AGT-GAG-AAG-GAA-GTG-GAC-TCT-3' \\
antisense & 5'-ATG-TTC-TTC-TCT-GTG-ACC-CAG-TC-3' \\
MMP-9 & \\
Sense & 5'-CGG-AGC-ACG-GAG-ACG-GGT-AT-3' \\
Antisense & 5'-TGA-AGG-GGA-AGA-CGC-ACA-GC-3' \\
Claudin-1 & \\
Sense & 5'-TCA-GCA-CTG-CCC-TGC-CCC-AGT-3' \\
Antisense & 5'-TGG-TGT-TGG-GTA-AGA-GGT-TGT-3' \\
Claudin-2 & \\
Sense & 5'-ACA-CAC-AGC-ACA-GGC-ATC-AC-3' \\
Antisense & 5'-TCT-CCA-ATC-TCA-AAT-TTC-ATG-C-3' \\
Claudin-3 & \\
Sense & 5'-AAG-GCC-AAG-ATC-ACC-ATC-GTG-3' \\
Antisense & 5'-AGA-CGT-AGT-CCT-TGC-GGT-CGT-3' \\
Claudin-4 & \\
Sense & 5'-TGG-ATG-AAC-TGC-GTG-GTG-CAG-3' \\
Antisense & 5'-GAG-GCG-GCC-CAG-CCG-ACG-TA-3' \\
GAPDH & \\
Sence & 5'-CGG-AGT-CAA-CGG-ATT-TGG-TCG-TAT-3' \\
Antisense & 5'-AGC-CTT-CTC-CAT-GGT-GGT-GAA-GAC-3' \\
\end{tabular}

$R N A$ extraction and reverse transcription-PCR. Following the manufacturer's instructions, an RNeasy kit (Qiagen, La Jolla, CA, USA) was used for preparation of total RNA, which was primed with random hexamers for synthesis of complementary DNA using AMV reverse transcriptase (Amersham Co., Arlington Heights, IL, USA), using DNAse I (1 U/ $\mu$ g RNA) pretreated total mRNA. Polymerase chain reaction (PCR) was performed in a Mastercycler (Eppendorf, Hamburg, Germany) using the primers indicated in Table II. Conditions for PCR reactions were $1 \times\left(94^{\circ} \mathrm{C}\right.$ for $\left.3 \mathrm{~min}\right), 35 \times\left(94^{\circ} \mathrm{C}\right.$ for $45 \mathrm{sec} ; 58^{\circ} \mathrm{C}$ for $45 \mathrm{sec}$; and $72^{\circ} \mathrm{C}$ for $\left.1 \mathrm{~min}\right)$, and $1 \times\left(72^{\circ} \mathrm{C}\right.$ for $10 \mathrm{~min}$ ). Amplification products obtained by PCR were electrophoretically separated on $1 \%$ agarose gel and visualized by ethidium bromide (EtBr) staining.

Protein extraction and Western blot analysis. Total cell lysates from cells were prepared in an extraction buffer $[25 \mathrm{mM}$ Tris- $\mathrm{Cl}$ ( $\mathrm{pH} 7.5$ ), $250 \mathrm{mM} \mathrm{NaCl}, 5 \mathrm{mM}$ ethylendiaminetetra acetic acid, $1 \%$ nonidet $\mathrm{P}-40,0.1 \mathrm{mM}$ sodium orthovanadate, $2 \mu \mathrm{g} / \mathrm{ml}$ leupeptin, and $100 \mu \mathrm{g} / \mathrm{ml}$ phenylmethylsulfonyl fluoride]. A Bio-Rad protein assay kit (Bio-Rad Laboratories, Hercules, CA, USA) was used for determination of protein concentration. For Western blot analysis, proteins $(50 \mu \mathrm{g})$ were separated by $8-13 \%$ sodium dodecyl sulfate (SDS)-polyacrylamide gel

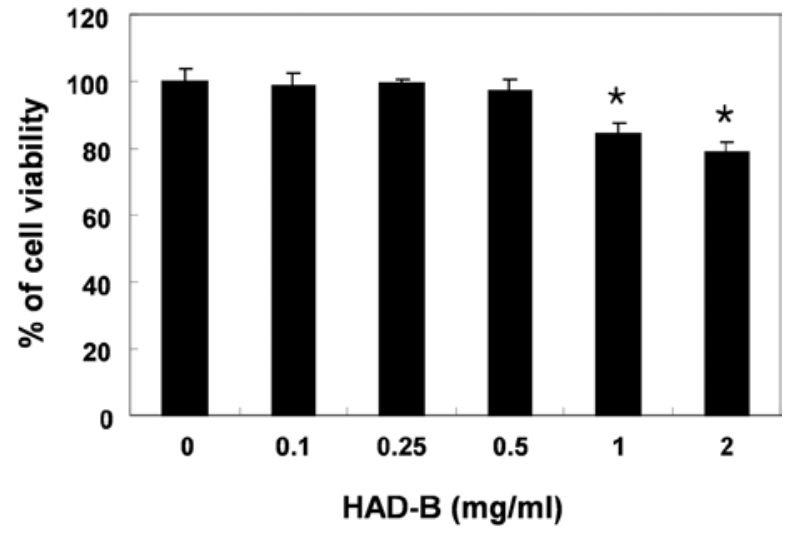

Figure 1. Effects of HAD-B on cell viability in NCI-H460 cells. Cells were seeded at an initial density of $2.5 \times 10^{5}$ cells per $60-\mathrm{mm}$ plate, incubated for $24 \mathrm{~h}$, and treated with various concentrations of HAD-B for $48 \mathrm{~h}$. Cell viability was measured using an MTT assay. Each point represents the mean \pm SD of three independent experiments. A Student's t-test was used for determination of significance ( $\mathrm{p}<0.05$ vs. untreated control).

electrophoresis and then electrotransferred to a nitrocellulose membrane (Schleicher \& Schuell Bioscience, Inc., Keene, NH, USA). Membranes were blocked with 5\% skim milk for $1 \mathrm{~h}$, and then subjected to immunoblot analysis using the desired antibodies. Proteins were then visualized by the enhanced chemiluminescence (ECL) method, according to the recommended procedure (Amersham Co.). Primary antibodies were purchased from Santa Cruz Biotechnology Inc. (Santa Cruz, CA, USA) and Invitrogen (Carlsbad, CA, USA). Peroxidase-labeled donkey anti-rabbit immunoglobulin and peroxidase-labeled sheep anti-mouse immunoglobulin were purchased from Amersham Co.

Gelatin zymographic analysis of secreted MMPs. Following incubation with various concentrations of HAD-B for $48 \mathrm{~h}$, cell culture supernatants were collected and centrifuged at $400 \mathrm{x} \mathrm{g}$ for $5 \mathrm{~min}$. Cell-free supernatant was mixed with $2 \mathrm{X}$ sample buffer (Invitrogen) and zymography was performed using precast gels (10\% polyacrylamide and $0.1 \%$ gelatin). Following electrophoresis, gels were washed twice at room temperature for $30 \mathrm{~min}$ in $2.5 \%$ Triton X-100, subsequently washed in buffer containing $50 \mathrm{mM}$ Tris- $\mathrm{HCl}, 150 \mathrm{mM} \mathrm{NaCl}$, $5 \mathrm{mM} \mathrm{CaCl}_{2}, 1 \mu \mathrm{M} \mathrm{ZnCl}_{2}$, and $0.02 \% \mathrm{NaN}_{3}$ at $\mathrm{pH} 7.5$, and incubated in this buffer at $37^{\circ} \mathrm{C}$ for $24 \mathrm{~h}$. Thereafter, gels were stained with $0.5 \%(\mathrm{w} / \mathrm{v})$ Coomassie brilliant blue G-250 (Bio-Rad Laboratories) for $1 \mathrm{~h}$, followed by light de-staining in methanol:acetic acid:water (3:1:6). Areas of gelatinolytic activity appear as clear bands on the Coomassie stained blue background. Gels were scanned and images were processed by extraction of the blue channel signal, converting it to black and white, and inverting it for quantification of gelatinolytic activities from the integrated optical density (21).

Statistical analysis. All data are presented as the mean \pm SD. The unpaired Student's t-test was used for determination of significant differences among the groups. $p<0.05$ was accepted as an indication of statistical significance. All of the figures shown in this study were obtained from at least three independent experiments. 


\section{Time (h)}

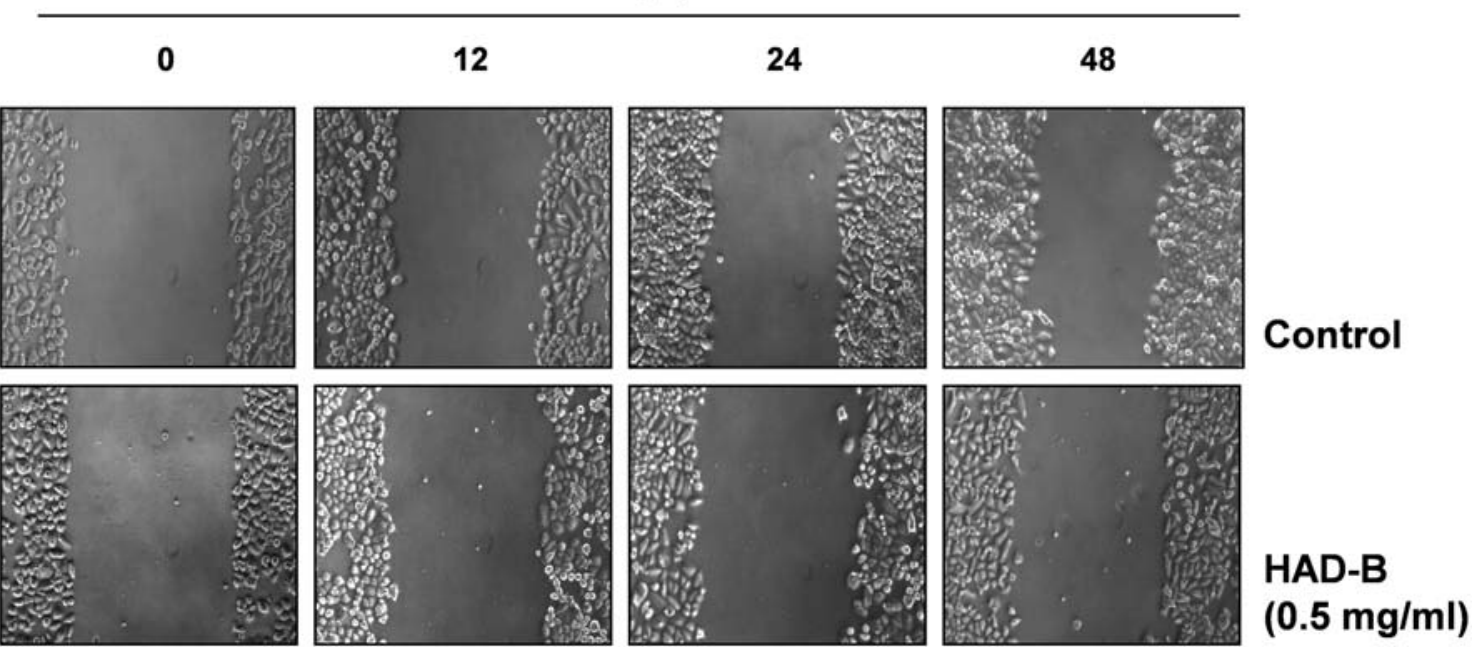

Figure 2. Inhibition of cell motility by HAD-B in NCI-H460 cells. Cells were grown to confluency on 30 -mm cell culture dishes; a scratch was then made through the cell layer using a pipette tip. After washing with PBS, serum-free media (to prevent cell proliferation) containing either vehicle or HAD-B (0.5 mg/ml) was added for the indicated times. Photographs of the wounded area were taken for evaluation of cell movement into the wounded area.

A

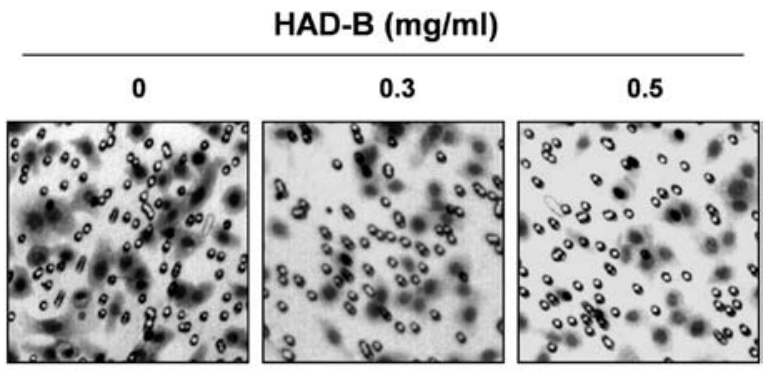

B

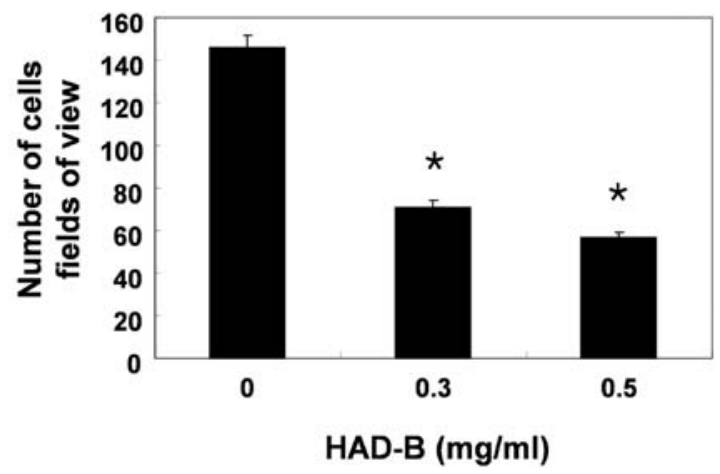

Figure 3. Effects of HAD-B on cell invasion in NCI-H460 B cells. (A) Cells pretreated with 0.3 or $0.5 \mathrm{mg} / \mathrm{ml}$ of HAD-B for $6 \mathrm{~h}$ were plated onto the apical side of matrigel coated filters in serum-free medium containing either vehicle or HAD-B. Medium containing $20 \%$ FBS was placed in the basolateral chamber to act as a chemoattractant. After $48 \mathrm{~h}$, cells on the apical side were wiped off using a Q-tip. Next, cells on the bottom of the filter were stained using hematoxylin and eosin Y, and then counted. (B) Data are shown as the mean of triplicate samples and represent invasive cell numbers, compared with those of control cells. "p $<0.05$ vs. untreated control.

\section{Results}

Inhibition of cell viability and migration by $H A D-B$ treatment in NCI-H460 cells. In order to determine whether
HAD-B induces a decrease in cell growth, NCI-H460 cells were stimulated with various concentrations of HAD-B and cell viability was then measured by an MTT assay. As shown in Fig. 1, after $48 \mathrm{~h}$ of HAD-B treatment, low concentrations of HAD-B $(0.1-0.5 \mathrm{mg} / \mathrm{ml})$ did not induce a reduction in cell viability, whereas high concentrations of HAD-B $(\geq 1.0 \mathrm{mg} / \mathrm{ml})$ caused a significant decrease in cell viability. When compared with the control, treatment with 1.0 and $2.0 \mathrm{mg} / \mathrm{ml}$ of HAD-B caused $\sim 14.9$ and $21.4 \%$ inhibition of cell growth, respectively. Wound healing experiments were performed for determination of whether or not HAD-B inhibits motility of NCI-H460 cells. Results demonstrated that $0.5 \mathrm{mg} / \mathrm{ml}$ of HAD-B, which was not cytotoxic, as shown by MTT assay, induced a time-dependent delay of the motility of NCI-H460 cells, compared with that of control cells (Fig. 2).

Inhibition of cell invasion by HAD-B in NCI-H460 cells. Using a Boyden chamber invasion assay, we next attempted to determine whether the inhibitory effects of HAD-B were connected to the decreased activity of cell invasion. As shown in Fig. 3, HAD-B treatment resulted in markedly reduced cell invasion through the Matrigel chamber in a concentration-dependent manner, suggesting that the inhibitory effects of cell migration were associated with inhibition of invasive activity in NCI-H460 cells.

Induction of TIMP-1 and TIMP-2 expression by HAD-B in $\mathrm{NCI}-\mathrm{H} 460 \mathrm{cells}$. Migration influences metastasis and invasion of the basement membrane is primarily mediated by gelatinase MMPs and their inhibitors, TIMPs; therefore, we tested the effects of HAD-B on levels of TIMP-1 and TIMP-2 expression. Results of RT-PCR showed that HAD-B induced a concentrationdependent increase of TIMP-1, as well as TIMP-2 mRNA levels, which was connected with concurrent up-regulation of their protein levels, as determined by Western blotting (Fig. 4), suggesting that increase of TIMPs proteins by HAD-B could inhibit the activity of MMPs. 
A

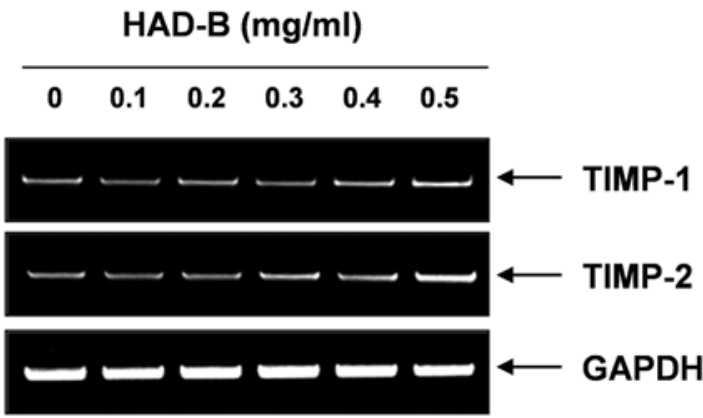

B

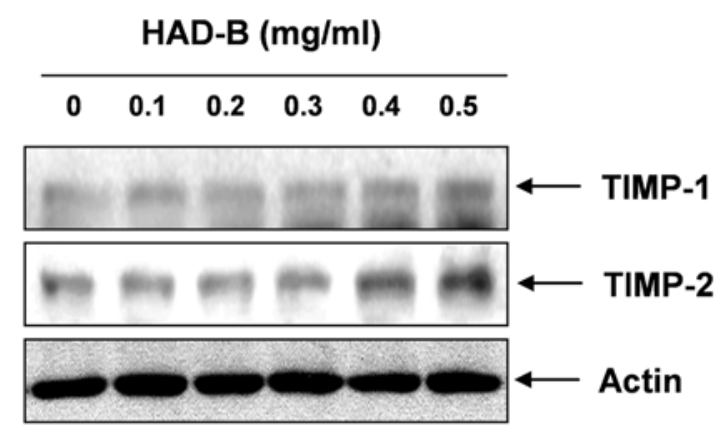

Figure 4. Induction of TIMP-1 and TIMP-2 expression by HAD-B in NCI-H460 cells. (A) Cells were treated with the indicated concentrations of HAD-B for $48 \mathrm{~h}$. Total RNAs were isolated and reverse-transcribed. Resulting cDNAs were then subjected to PCR and the reaction products were subjected to electrophoresis in a $1 \%$ agarose gel and visualized by $\mathrm{EtBr}$ staining. GAPDH was used as an internal control. (B) Cells grown under the same conditions as (A) were sampled, lysed, and $50 \mu \mathrm{g}$ of proteins were separated by electrophoresis on SDS-polyacrylamide gels. Western blotting was then performed using anti-TIMP-1 and anti-TIMP-2 antibodies, and an ECL detection system. Actin was used as an internal control.

Inhibition of the activity of MMP-2 and MMP-9 by HAD-B in NCI-H460 cells. We next investigated the effects of HAD-B on mRNA and protein levels of MMP-2 and MMP-9, and their activities. Results showed that HAD-B induced a concentrationdependent decrease in MMP-2 and MMP-9 mRNA levels (Fig. 5A), which was also connected with concurrent downregulation of their protein levels (Fig. 5B). In addition, we performed gelatin zymographic analysis in order to determine whether or not the inhibitory effects on mRNA levels of MMP-2 and MMP-9 were associated with down-regulation of their activities. As indicated in Fig. 5C, HAD-B induced a concentration-dependent decrease of MMP-2 and -9 activities. These results suggest that the anti-invasive effects of HAD-B are associated with increased TIMP-1 and TIMP-2 levels, as well as inhibition of MMP-2 and -9 levels, and their activity in NCI-H460 cells.

Enhancement of TJs tightening by HAD-B in NCI-H460 cells. In order to examine the relationship between TJs tightening and invasive activity of NCI-H460 cells treated with HAD-B, TER (a measure of tight junction formation) values were measured using an EVOM Epithelial Tissue Voltohmmeter. As shown in Fig. 6, incubation of cells with HAD-B resulted in a substantial concentration-dependent increase in their TER values, suggesting that HAD-B induced an increase in TJs function in NCI-H460 cells.
A

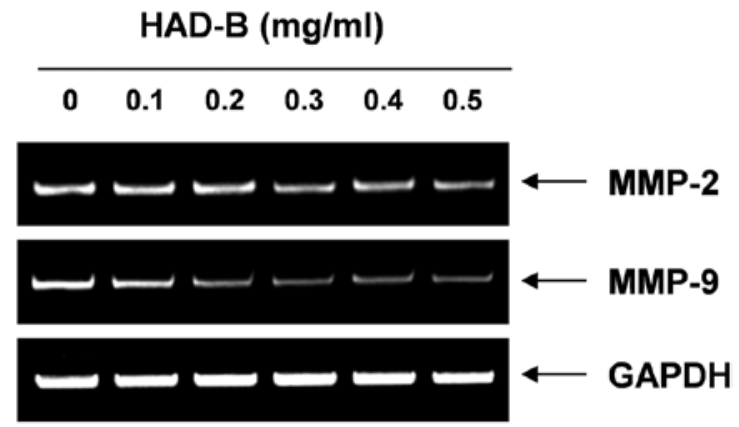

B

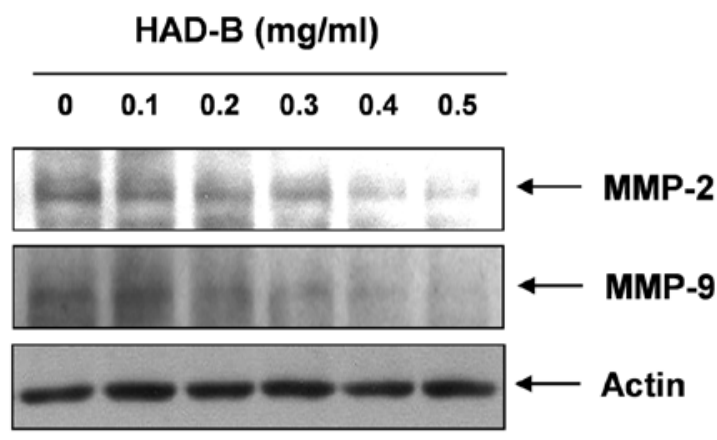

C HAD-B (mg/ml)

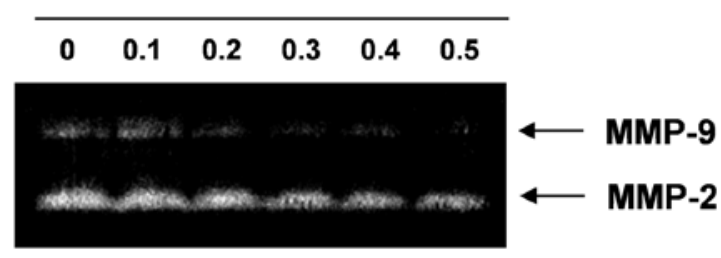

Figure 5. Inhibition of MMP-2 and MMP-9 expression and their activities by HAD-B in NCI-H460 cells. (A) Cells were treated with the indicated concentrations of HAD-B for $48 \mathrm{~h}$. Total RNAs were isolated and reversetranscribed. Resulting cDNAs were then subjected to PCR. The reaction products were subjected to electrophoresis in a $1 \%$ agarose gel and visualized by EtBr staining. GAPDH was used as an internal control. (B) Cells grown under the same conditions as (A) were sampled, lysed, and $50 \mu \mathrm{g}$ of proteins were separated by electrophoresis on SDS-polyacrylamide gels. Western blotting was then performed using anti-MMP-2 and anti-MMP-9 antibodies, and an ECL detection system. Actin was used as an internal control. (C) After incubation with HAD-B under the same conditions as those of (A), medium was collected, and the activities of MMP-2 and -9 were measured by zymography, as described in Materials and methods.

Modulation of TJ-related factors by HAD-B in NCI-H46O cells. In order to elucidate the mechanism by which HAD-B enhances TJ activity and reduces invasive activity in NCI-H460 cells, we next determined the levels of TJ regulators. As shown in Fig. 7, HAD-B-treated cells showed dose-dependent down-regulation of both transcriptional and translational levels of claudins (claudin-1, -2, -3, and -4), the most important components of the TJ (16), suggesting that this modulation contributed to TJs tightening.

\section{Discussion}

Metastasis is the sequential multistep process of the spread of cancer cells to tissues and organs beyond where the tumor originated and formation of new tumors. This process ultimately 


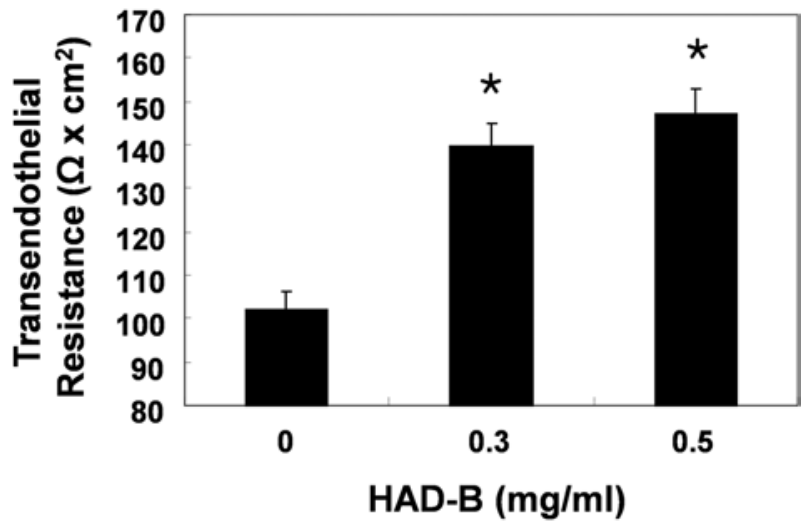

Figure 6. Increase of TER values by HAD-B in NCI-H460 cells. Cells were treated with 0.3 or $0.5 \mathrm{mg} / \mathrm{ml}$ of HAD-B for $48 \mathrm{~h}$, and TER values were measured using an EVOM Epithelial Tissue Voltohmmeter, as described in Materials and methods. Results are shown as the mean \pm SD of three independent experiments. A Student's t-test was used for determination of significance $($ p $\mathrm{p}<0.05$ vs. untreated control).

leads to outgrowth in a different organ from the one in which it originated. Cancer cell migration and invasion are critical steps during metastasis; therefore, inhibition of cell migration and invasion are important mechanisms for consideration in development of anti-cancer drugs. The aim of this study was to investigate the question of whether HAD-B has potent anti-metastasis activities in human lung carcinoma NCI-H460 cells. We found that HAD-B induced marked inhibition of cell motility and invasive activity through decreasing MMP activity and tightening of TJs.

MMPs are important proteolytic enzymes in organ development and tissue regeneration; however, they also play important roles in cancer cell invasion. Thus, tumor metastasis can be inhibited by blockade of MMP synthesis and their activity $(6,7)$. Activity of MMPs is tightly controlled by transcriptional activation, by a complex proteolytic activation cascade, and by an endogenous system of TIMPs. TIMPs inhibit MMPs by formation of stoichiometric complexes for regulation of matrix turnover $(8,9)$. Treatment with $<0.5 \mathrm{mg} / \mathrm{ml}$ of HAD-B, which was not cytotoxic, as determined by MTT assay, resulted in marked inhibition of cell motility and invasive activity in NCI-H460 cells; therefore, we investigated the question of whether or not the inhibitory effects of HAD-B were associated with modulation of TIMPs and MMPs expression or their activities. Our results indicated that HAD-B induced marked concentration-dependent inhibition of MMP-2 and MMP-9 expression, as well as their enzymatic activities. On the contrary, the transcriptional and translational levels of both TIMP-1 and TIMP-2 showed concentration-dependent up-regulation in response to HAD-B treatment. The present data demonstrated that HAD-B-induced inhibition of cell motility and invasion is related to down-regulation of MMP-2 and -9 activities through elevation of TIMPs expression. Therefore, our results suggested that HAD-B may induce an increase of the TIMPs/ MMPs ratio as a key factor in regulation of the anti-metastatic process, which subsequently blocks degradation of ECM and leads to inhibition of cell invasion.

A frequent association of development of human cancer with failure of epithelial cells to form TJs and to establish
A

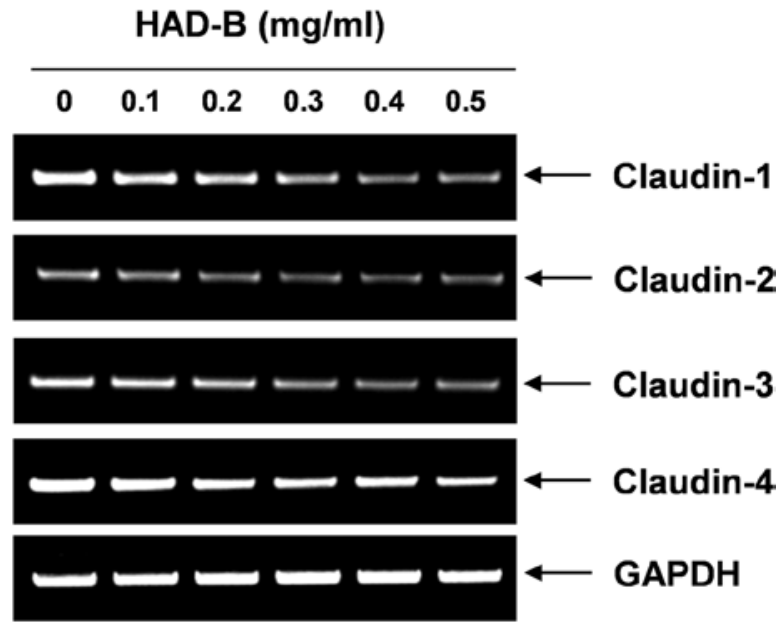

B

HAD-B (mg/ml)

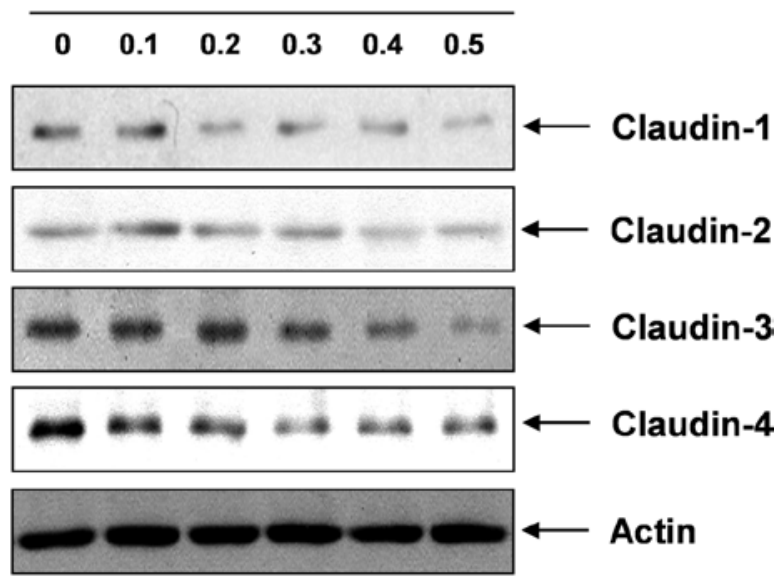

Figure 7. Effects of HAD-B on expression of claudins in NCI-H460 cells. (A) Cells were treated with the indicated concentrations of HAD-B for $48 \mathrm{~h}$. Total RNAs were isolated and reverse-transcribed using the indicated primers. Resulting cDNAs were then subjected to PCR and the reaction products were subjected to electrophoresis in a $1 \%$ agarose gel and visualized by $\mathrm{EtBr}$ staining. GAPDH was used as an internal control. (B) Cells grown under the same conditions as (A) were sampled, lysed, and $50 \mu \mathrm{g}$ of proteins were separated by electrophoresis on SDS-polyacrylamide gels. Western blotting was then performed using the indicated antibodies, and an ECL detection system. Actin was used as an internal control.

correct apicobasal polarity has recently become increasingly clear $(3,22)$. These observations indicate that changes of permeability properties and loss of cell polarity are hallmarks of epithelial cell tumorigenesis. Actually, TJs are critical structures in maintenance of these functions in epithelial cells, and their modulation is observed in a number of epithelial cancers $(10,11)$. These observations indicate that disruption of TJs and dysregulation of their composite proteins play critical roles in cancer progression, invasion, and metastasis. On the other hand, Soler et al (10) first demonstrated that the TER of colon carcinoma tissue was significantly lower than that of normal colon tissues, but showed higher transepithelial paracellular permeability, which confirmed the loss of TJs. In addition, some previous studies have shown that many anticancer agents are inhibitory to motility and invasiveness, and that they act by enhancement of transepithelial paracellular 
permeability $(18,21,23-26)$. In the present study, we examined changes of TER values in order to investigate the relationship between anti-invasive activity and TJs in response to HAD-B treatment. Our results clearly showed that HAD-B treatment induced a dose-dependent increase of the TER values of NCI-H460 cells, an effect associated with inhibition of motility and invasiveness. These results indicate that treatment with HAD-B may result in prevention or reversal of TJ leakiness.

TJ structure is representative of the conglomerate of molecules that constitute, associate with, or regulate TJs, and a number of proteins, as components of TJs, were identified. Among these, 24 members of the claudin family, which are transmembrane proteins with extracellular domains, were identified. Claudins interact with other claudins to form homodimers or heterodimers to produce paired strands between cells for regulation of paracellular permeability $(12,13)$. A significant amount of previous evidence has indicated that disruption of TJs, with concomitant dysregulation of TJ proteins, is an early event in cancer cell invasion and metastasis, and the nature of the dysregulation is highly cancer type specific $(15,27-31)$. These observations indicate that claudins are dysregulated in many types of cancers, and may prove to be useful biomarkers for detection and diagnosis of certain cancers. Therefore, we investigated the effects of HAD-B on the levels of claudin family members; the data showed that treatment with HAD-B resulted in significantly inhibited expression of claudin proteins, including claudin-1, $-2,-3$, and -4 at both the transcriptional and translational levels. The data suggested that the anti-invasive activity of HAD-B was associated with tightening of TJs through down-regulation of claudin family members.

In summary, the present results revealed that HAD-B has an anti-metastatic property, which is accompanied by tightening of TJs and repression of MMP activities while concurrently inhibiting claudin expression, as well as inducing TIMP expression, respectively. Although we will need to validate this study, our findings point to a novel anti-cancer mechanism by HAD-B, and the results also indicate that HAD-B may be a potential chemotherapeutic agent for use in decreasing the risk for development of lung cancer.

\section{Acknowledgements}

This study was supported by Basic Science Research Program through the National Research Foundation of Korea (NRF) funded by the Ministry of Education, Science, and Technology (2010-0001730) and Blue-Bio Industry RIC at Dong-Eui University as a RIC (08-06-07) program of KIAT under Ministry of Knowledge Economy, South Korea.

\section{References}

1. Hart IR, Goode NT and Wilson RE: Molecular aspects of the metastatic cascade. Biochem Biophys Acta 989: 65-84, 1989.

2. Jiang WG, Puntis MCA and Hallet MB: The molecular and cellular basis of cancer invasion and metastasis and its implications for treatment. Br J Surg 81: 1576-1590, 1994.

3. Martin TA and Jiang WG: Loss of tight junction barrier function and its role in cancer metastasis. Biochim Biophys Acta 1788 872-891, 2009.

4. Duffy MI, Maguire TM, Hill A, McDermott E and O'Higgins N: Metalloproteinases: role in breast carcinogenesis, invasion and metastasis. Breast Cancer Res 2: 252-257, 2000.
5. Vihinen P, Ala-aho R and Kähäri VM: Matrix metalloproteinases as therapeutic targets in cancer. Curr Cancer Drug Targets 5: 203-220, 2005

6. Mook OR, Frederiks WM and Van Noorden CJ: The role of gelatinases in colorectal cancer progression and metastasis. Biochim Biophys Acta 1705: 69-89, 2004.

7. Matrisian LM: The matrix-degrading metalloproteinases. Bioessays 14: 455-463, 1992

8. Uzui H, Harpf A, Liu M, Doherty TM, Shukla A and Chai N: Increased expression of membrane type 3-matrix metalloproteinase in human atherosclerotic plaque: role of activated macrophages and inflammatory cytokines. Circulation 106: 3024-3030, 2002.

9. Lambert E, Dasse E, Haye B and Petitfrere E: TIMPs as multifacial proteins. Crit Rev Oncol Hematol 49: 187-198, 2004.

10. Soler AP, Miller RD, Laughlin KV, Carp NZ, Klurfeld DM and Mullin JM: Increased tight junctional permeability is associated with the development of colon cancer. Carcinogenesis 20: 1425-1431, 1999

11. Schneeberger EE and Lynch RD: The tight junction: a multifunctional complex. Am J Physiol Cell Physiol 286: C1213-C1228, 2004.

12. Morin PJ: Claudin proteins in human cancer: promising new targets for diagnosis and therapy. Cancer Res 65: 9603-9606, 2005.

13. Van Itallie CM and Anderson JM: Claudins and epithelial paracellular transport. Annu Rev Physiol 68: 403-429, 2006.

14. Soini Y: Claudins 2, 3, 4, and 5 in Paget's disease and breast carcinoma. Hum Pathol 35: 1531-1536, 2004.

15. Rangel LB, Agarwal R, D'Souza T, Pizer ES, Alò PL, Lancaster WD, Gregoire L, Schwartz DR, Cho KR and Morin PJ: Tight junction proteins claudin-3 and claudin- 4 are frequently overexpressed in ovarian cancer but not in ovarian cystadenomas. Clin Cancer Res 9: 2567-2575, 2003.

16. Kominsky SL: Claudins: emerging targets for cancer therapy. Expert Rev Mol Med 8: 1-11, 2006.

17. Bello IO, Vilen ST, Niinimaa A, Kantola S, Soini Y and Salo T: Expression of claudins 1, 4, 5, and 7 and occludin, and relationship with prognosis in squamous cell carcinoma of the tongue. Hum Pathol 39: 1212-1220, 2008.

18. Van Deun K, Pasmans F, Van Immerseel F, Ducatelle R and Haesebrouck F: Butyrate protects Caco-2 cells from Campylobacter jejuni invasion and translocation. Br J Nutr 100: 480-484, 2008

19. Bang JY, Kim EY, Shim TK, Yoo HS, Lee YW, Kim YS, Cho CK, Choi Y, Jeong HJ and Kang IC: Analysis of anti-angiogenic mechanism of HangAmDan-B (HAD-B), a Korean traditional medicine, using antibody microarray chip. BioChip J 4: 350-355, 2010.

20. Kim SO, Kwon JI, Jeong YK, Kim GY, Kim ND and Choi YH: Induction of Egr-1 is associated with anti-metastatic and antiinvasive ability of $\beta$-lapachone in human hepatocarcinoma cells. Biosci Biotechnol Biochem 71: 2169-2176, 2007.

21. Lee YR, Noh EM, Jeong EY, Yun SK, Jeong YJ, Kim JH, Kwon KB, Kim BS, Lee SH, Park CS and Kim JS: Cordycepin inhibits UVB-induced matrix metalloproteinase expression by suppressing the NF- $\kappa \mathrm{B}$ pathway in human dermal fibroblasts. Exp Mol Med 41: 548-554, 2009.

22. Latorre IJ, Roh MH, Frese KK, Weiss RS, Margolis B and Javier RT: Viral oncoprotein-induced mislocalization of select PDZ proteins disrupts tight junctions and causes polarity defects in epithelial cells. J Cell Sci 118: 4283-4293, 2005.

23. Gitter AH, Bendfeldt K, Schmitz H, Schulzke JD, Bentzel CJ and Fromm M: Epithelial barrier defects in HT-29/B6 colonic cell monolayers induced by tumor necrosis factor- $\alpha$. Ann NY Acad Sci 915: 193-203, 2000.

24. Verghese GM, Gutknecht MF and Caughey GH: Prostasin regulates epithelial monolayer function: cell-specific Gpld1mediated secretion and functional role for GPI anchor. Am J Physiol Cell Physiol 291: C1258-C1270, 2006.

25. Kim SO, Choi BT, Choi IW, Cheong J, Kim GY, Kwon TK, Kim ND and Choi YH: Anti-invasive activity of histone deacetylase inhibitors via the induction of Egr-1 and the modulation of tight junction-related proteins in human hepatocarcinoma cells. BMB Rep 42: 655-660, 2009.

26. Shin DY, Kim GY, Kim JI, Yoon MK, Kwon TK, Lee SJ, Choi YW, Kang HS, Yoo YH and Choi YH: Anti-invasive activity of diallyl disulfide through tightening of tight junctions and inhibition of matrix metalloproteinase activities in LNCaP prostate cancer cells. Toxicol In Vitro 24: 1569-1576, 2010. 
27. Kominsky SL, Argani P, Korz D, Evron E, Raman V, Garrett E, Rein A, Sauter G, Kallioniemi OP and Sukumar S: Loss of the tight junction protein Claudin-7 correlates with histological grade in both ductal carcinoma in situ and invasive ductal carcinoma of the breast. Oncogene 22: 2021-2033, 2003.

28. Kominsky SL, Vali M, Korz D, Gabig TG, Weitzman SA, Argani P and Sukumar S: Clostridium perfringens enterotoxin elicits rapid and specific cytolysis of breast carcinoma cells mediated through tight junction proteins Claudin 3 and 4 . Am J Pathol 164: 1627-1633, 2004.

29. Tokés AM, Kulka J, Paku S, Szik A, Páska C, Novák PK Szilák L, Kiss A, Bögi K and Schaff Z: Claudin-1, -3 and -4 proteins and mRNA expression in benign and malignant breast lesions: a research study. Breast Cancer Res 7: R296-R305, 2005.
30. Cunningham SC, Kamangar F, Kim MP, Hammoud S, Haque R, Iacobuzio-Donahue CA, Maitra A, Ashfaq R, Hustinx S, Heitmiller RE, Choti MA, Lillemoe KD, Cameron JL, Yeo CJ, Schulick R and Montgomery E: Claudin-4, mitogen activated protein kinase kinase 4, and stratifin are markers of gastric adenocarcinoma precursor lesions. Cancer Epidemiol Biomarkers Prev 15: 281-287, 2004

31. Michl P, Barth C, Buchholz M, Lerch MM, Rolke M, Holzmann KH, Menke A, Fensterer H, Giehl K, Löhr M, Leder G, Iwamura T, Adler G and Gress TM: Claudin-4 expression decreases invasiveness and metastatic potential of pancreatic cancer. Cancer Res 63: 6265-6271, 2003. 